\title{
Global proteome profiling of human livers upon ischemia/reperfusion treatment
}

\author{
Haijian Cai ${ }^{1,2 \dagger}$, Shunli Qi ${ }^{3+}$, Qi Yan ${ }^{1 \dagger}$, Jun Ling ${ }^{3}$, Jian Du ${ }^{1,2^{*}}$ (D) and Lijian Chen ${ }^{3 *}$
}

\begin{abstract}
Hepatic ischemia/reperfusion (I/R) injury represents a major risk factor for liver transplantation and is related to graft dysfunction and acute/chronic rejection. However, a significant part of these processes remain poorly characterized. To reveal differences in the proteome during liver I/R injury, we collected human liver biopsy samples during hepatectomy before and after the Pringle maneuver and conducted a TMT-based proteomic analysis through quantitative high-throughput mass spectrometry. We used a fold-change threshold of 1.3 and a $t$-test $p$-value $<0.05$ as the criteria to identify 5,257 total quantifiable proteins. The levels of 142 proteins were increased, while the levels of 103 proteins were decreased in response to hepatic I/R treatment. Bioinformatic analysis further revealed that these differentially expressed proteins are mainly involved in multiple biological functions and enzyme-regulated metabolic pathways. Most proteins whose expression was changed are related to the defense, immune and inflammatory responses as well as lipid and steroid metabolic processes. Based on this finding, we developed a panel for targeted proteomic analysis and used the parallel reaction monitoring (PRM) method, QPCR and western blotting experiments to validate alterations in the expression of some of the identified proteins. The upregulated proteins were found to be involved in immunity and inflammatory responses, and downregulated proteins were enriched in metabolic pathways. This study therefore may provide a research direction for the design of new therapeutic strategies for hepatic ischemia/reperfusion injury.
\end{abstract}

Keywords: Hepatic ischemia/reperfusion, Human, Proteomics, TMT

\section{Introduction}

Severe intraoperative bleeding represents a major risk during hepatectomy. To avoid massive blood loss, continuous or intermittent vascular clamping of the hepatic artery and portal vein, the so-called Pringle maneuver, is an efficient method to reduce hemorrhage. However, the Pringle maneuver can lead directly to reperfusion in the liver. Liver ischemia/reperfusion (I/R) injury is a

\footnotetext{
*Correspondence: dujane@163.com; dujian@ahmu.edu.cn; chenlijian77@126. com

${ }^{\dagger}$ Haijian Cai, Shunli Qi and Qi Yan contributed equally to this study ${ }^{1}$ Department of Biochemistry and Molecular Biology, School of Basic Medical Sciences, Anhui Medical University, Hefei, Anhui 230032, People's Republic of China

${ }^{3}$ Department of Anesthesiology, the First Affiliated Hospital of Anhui Medical University, Hefei, Anhu 230032, People's Republic of China Full list of author information is available at the end of the article
}

source of morbidity and mortality of liver surgeries, such as hepatectomy and transplantation, hemorrhagic shock and tissue resection $[1,2]$. Ischemia/reperfusion injury (IRI) is tissue damage caused when blood supply returns to tissue (reperfusion) after a period of ischemia or lack of oxygen (anoxia or hypoxia). Two distinct stages of liver IRI with unique mechanisms of hepatic damage have been identified. Ischemic injury, a process of localized cellular metabolic disturbance, results from glycogen consumption, a lack of the oxygen supply and ATP depletion and lead to initial parenchymal cell death. During an ischemic period, hepatocytes switch their cellular metabolism from aerobic to anaerobic pathways, which causes various hepatocellular dysfunctions. Reperfusion injury, which follows ischemic injury, results from not only metabolic disturbances but also a profound inflammatory immune response that involves both direct and indirect

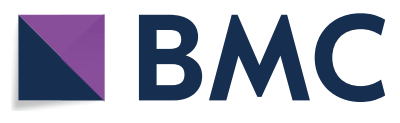

(c) The Author(s) 2021. This article is licensed under a Creative Commons Attribution 4.0 International License, which permits use, sharing, adaptation, distribution and reproduction in any medium or format, as long as you give appropriate credit to the original author(s) and the source, provide a link to the Creative Commons licence, and indicate if changes were made. The images or other third party material in this article are included in the article's Creative Commons licence, unless indicated otherwise in a credit line to the material. If material is not included in the article's Creative Commons licence and your intended use is not permitted by statutory regulation or exceeds the permitted use, you will need to obtain permission directly from the copyright holder. To view a copy of this licence, visit http://creativeco mmons.org/licenses/by/4.0/. The Creative Commons Public Domain Dedication waiver (http://creativecommons.org/publicdomain/ zero/1.0/) applies to the data made available in this article, unless otherwise stated in a credit line to the data. 
cytotoxic mechanisms [3]. The absence of oxygen and nutrients in the blood during the ischemic period creates a condition in which the restoration of circulation results in inflammation and oxidative damage through the induction of oxidative stress rather than the restoration of normal function. Several factors and mechanisms implicated in the hepatic IRI process are anaerobic metabolism, mitochondria damage, oxidative stress and ROS, intracellular calcium overload, liver Kupffer cells and neutrophils, nitric oxide, cytokines and chemokines [3-7]. Indeed, liver IRI remains a major problem in clinical transplantation, causing more than $10 \%$ of early transplant failures and leading to a higher incidence of both acute and chronic rejection $[8,9]$. Despite the obvious clinical importance of liver $I / R$, the mechanisms that account for $I / R$ injury are only partially understood and remain one of the most understudied areas in clinical and experimental transplantation [3].

To understand the molecular bases of liver I/R-induced injury and develop novel approaches for injury control, it is important to identify genes/proteins whose expression/function is directly modified by the damage itself. However, due to limited knowledge of the functional molecules involved in $\mathrm{I} / \mathrm{R}$ injury and the complexity of the regulatory mechanisms of the liver response, the identification of molecular targets for therapeutic intervention is very difficult. Nevertheless, rapid progress in both protein separation and identification techniques has made mass spectrometry a powerful tool with which to characterize proteins in a more global way by the simultaneous evaluation of hundreds of protein species, allowing the study of biological responses in complex systems [10-12]. In the present study, we performed a quantitative proteomics study of hepatic hemangioma patients who underwent hepatectomy before and after the Pringle maneuver. Here, we found that 142 proteins were significantly upregulated and that 103 proteins were downregulated upon $\mathrm{I} / \mathrm{R}$ treatment. These findings may assist in designing new therapeutic strategies for hepatectomy, including organ preservation for liver transplantation.

\section{Methods}

\section{Sample collection and preparation}

Six patients with hepatic hemangioma underwent hepatectomy receiving Pringle maneuver which caused hepatic ischemia reperfusion injury (mean age 50.3, range 36-65). The median ischemia times were 17 min (mean time $17 \mathrm{~min}$, range 9-22 $\mathrm{min}$ ), and the reperfusion times were all $10 \mathrm{~min}$. The liver samples $\left(0.8-1.0 \mathrm{~cm}^{3}\right)$ were obtained away from the resection site of the liver prior to Pringle maneuver (control group) and 10 min after restoration of blood supply (ischemia/reperfusion group) respectively during the surgery, and snapped frozen on liquid nitrogen for 1-2 min, then moved quickly and stored at $-80{ }^{\circ} \mathrm{C}$ until analysis. An informed written consent was obtained from all patients. The patients were recruited at the First Affiliated Hospital of Anhui Medical University and approved by the institutional ethics committee (No: 20180145).

\section{Protein extraction}

The sample was sonicated three times on ice using a high intensity ultrasonic processor (Scientz) in four volumes of lysis buffer (8 M urea, $300 \mathrm{mM}$ Tris pH8, 4\% CHAPS, $1 \mathrm{MNaCl}, 1 \%$ Protease Inhibitor Cocktail). The remaining debris was removed by centrifugation at $12,000 \mathrm{~g}$ at $4{ }^{\circ} \mathrm{C}$ for $10 \mathrm{~min}$. Finally, the supernatant was collected and the protein concentration was determined with BCA kit according to the manufacturer's instructions.

\section{Digestion and TMT labeling}

For digestion, the protein solution was reduced with $5 \mathrm{mM}$ dithiothreitol for $30 \mathrm{~min}$ at $56{ }^{\circ} \mathrm{C}$ and alkylated with $11 \mathrm{mM}$ iodoacetamide for $15 \mathrm{~min}$ at room temperature in darkness. The protein sample was then diluted by adding $100 \mathrm{mM}$ TEAB to urea concentration less than $2 \mathrm{M}$. Finally, trypsin was added at 1:50 trypsin-to-protein mass ratio for the first digestion overnight and 1:100 trypsin-to-protein mass ratio for a second $4 \mathrm{~h}$-digestion. After trypsin digestion, peptide was desalted by Strata X C18 SPE column (Phenomenex) and vacuum-dried. Peptide was reconstituted in $0.5 \mathrm{M}$ TEAB and processed according to the manufacturer's protocol for TMT kit. Briefly, one unit of TMT reagent was thawed and reconstituted in acetonitrile. The peptide mixtures were then incubated for $2 \mathrm{~h}$ at room temperature and pooled, desalted and dried by vacuum centrifugation.

\section{HPLC fractionation}

The protein digestion was then fractionated by high $\mathrm{pH}$ reverse-phase HPLC using Agilent 300 Extend C18 column (5 $\mu \mathrm{m}$ particles, $4.6 \mathrm{~mm}$ ID, $250 \mathrm{~mm}$ length). Briefly, peptides were first separated with a gradient of $2 \%$ to $60 \%$ acetonitrile in $10 \mathrm{mM}$ ammonium bicarbonate $\mathrm{pH} 8$ over $80 \mathrm{~min}$ into 80 fractions. Then, the peptides were combined into 18 fractions for the global proteome analysis as previously reported [13]. The tryptic peptides were fractionated into fractions by high $\mathrm{pH}$ reverse-phase HPLC using Agilent 300 Extend C18 column $(5 \mu \mathrm{m}$ particles, $4.6 \mathrm{~mm}$ ID, $250 \mathrm{~mm}$ length). Briefly, peptides were first separated with a gradient of $8 \%$ to $32 \%$ acetonitrile (pH 9.0) over 60 min into 60 fractions. Then, the peptides were combined into 18 fractions and dried by vacuum centrifuging. 


\section{LC-MS/MS analysis}

The peptides were dissolved in solvent A $(0.1 \%$ FA in $2 \% \mathrm{ACN}$ ), directly loaded onto a home-made reversedphase analytical column ( $15 \mathrm{~cm}$ length, $75 \mu \mathrm{m}$ i.d.). The gradient was comprised of an increase from 6 to $23 \%$ solvent B (0.1\% formic acid in $98 \%$ acetonitrile) over $26 \mathrm{~min}, 23 \%$ to $35 \%$ in $8 \mathrm{~min}$ and climbing to $80 \%$ in $3 \mathrm{~min}$ then holding at $80 \%$ for the last $3 \mathrm{~min}$, all at a constant flow rate of $400 \mathrm{~nL} / \mathrm{min}$ on an EASY-nLC 1000 UPLC system. The peptides were subjected to NSI source followed by tandem mass spectrometry (MS/ MS) in Q Exactive ${ }^{\mathrm{TM}}$ Plus (Thermo) coupled online to the UPLC. The applied electrospray voltage was $2.0 \mathrm{kV}$. The $\mathrm{m} / \mathrm{z}$ scan range was from 350 to 1,800 for full scan, and intact peptides were detected in the Orbitrap at a resolution of 70,000. Peptides were then selected for MS/MS using NCE setting as 28 and the fragments were detected in the Orbitrap at a resolution of 17,500. A data-dependent procedure was alternated between one MS scan followed by $20 \mathrm{MS} / \mathrm{MS}$ scans with $15.0 \mathrm{~s}$ dynamic exclusion. Automatic gain control (AGC) was set at 5E4. Fixed first mass was set as $100 \mathrm{~m} / \mathrm{z}$. Secondary mass spectral data was retrieved by using Maxquant (v1.5.2.8). Search parameter settings: the database was SwissProt Human (20,317 sequences), the anti-library was added to calculate the false positive rate (FDR) caused by random matching, and a common pollution library was added to the database to eliminate the contaminated protein in the identification results. The effect was set to Trypsin/P; the number of missed sites was set to 2 ; the minimum length of the peptide was set to 7 amino acid residues; the maximum number of peptides was set to 5 ; the primary precursor of the First search and Main search mass error tolerance was set to $20 \mathrm{ppm}$ and $5 \mathrm{ppm}$ respectively, and the mass error tolerance of the secondary fragment ions was $0.02 \mathrm{Da}$. The cysteine alkylation was set to a fixed modification, the variable modification was the oxidation of methionine and the N-terminal acetylation of the protein. The quantitative method was set to TMT-6 plex, and the FDR for protein identification and PSM identification was set to $1 \%$.

\section{Statistical analysis}

Data were expressed as mean \pm standard deviation, and the differences between groups were analyzed using Student's $t$ test, $p$ values $<0.05$ or 0.01 were considered to represent statistical differences or statistically significant differences. In order to obtain bioinformatics, the UniProt-GOA database (http://www.ebi.ac.uk/ GOA/) and the PANTHER (www.pantherdb.org) database were used.

\section{PRM}

The peptide samples were prepared according to the whole cell proteome analysis methodology described above. The proteins selected for PRM validation were based on the results of whole cell proteome. In addition, to determine the target peptides of each protein selected for PRM and their retention times, the peptide sample was initially run in a DDA mode using Q Exactive $^{\text {TM }}$ Plus (Thermo Fisher Scientific, Waltham, MA, USA), which was coupled to the UPLC online with the identical gradient to subsequent PRM analysis. Based on the results of this pre-experiment, peptides were selected and input as entries into the inclusion list, which would be detected in the PRM assay. In the subsequent PRM analysis, the peptide mixture was loaded onto an PicoFrit capillary column $(75 \mu \mathrm{m} \times 15 \mathrm{~cm}$, New Objective, Woburn, MA, USA) packed with ReproSilPur Basic C18 reverse phase resin $\left(1.9 \mu \mathrm{m}, 100 \mathrm{~A}^{\circ}\right.$, Dr. Maisch GmbH, Ammerbuch, Germany) and separated in an EASY-nLC 1000 UPLC system (Thermo Fisher Scientific, Waltham, MA, USA), with a gradient of $6 \%$ to $23 \%$ solvent $\mathrm{B}(0.1 \%$ formic acid in $98 \% \mathrm{ACN})$ over $38 \mathrm{~min}$, followed by $23-35 \%$ solvent B over $14 \mathrm{~min}$ and increasing to $80 \%$ solvent $\mathrm{B}$ over $4 \mathrm{~min}$, with a flow rate of $400 \mathrm{~nL} / \mathrm{min}$. The eluate was examined via mass spectrometry using Q Exactive ${ }^{\mathrm{TM}}$ Plus (Thermo Fisher Scientific, Waltham, MA, USA), which was coupled to the UPLC online. After a full-scan event, the MS/MS scans in PRM mode were triggered by inclusion list. A full mass spectrum was detected in the Orbitrap at a resolution of 70,000 (AGC target was set as $3 \mathrm{E}^{6}$; the maximum injection time was $50 \mathrm{~ms}$; and the $\mathrm{m} / \mathrm{z}$ range was 350-1200), followed by $20 \mathrm{MS} / \mathrm{MS}$ scans on the Orbitrap at a resolution of 17,500 (AGC target was $1 \mathrm{E}^{5}$, and the maximum injection time was $100 \mathrm{~ms}$ ) in a data independent procedure. Mass window for precursor ion selection was $1.6 \mathrm{~m} / \mathrm{z}$. The isolation window for MS/MS was set at $2.0 \mathrm{~m} / \mathrm{z}$. The NCE was $27 \%$ with HCD. Three biological replicates were performed. PRM data were analyzed using Skyline (v.3.6) software. The following parameters were set for this analysis: (1) enzyme, trypsin $[\mathrm{KR} / \mathrm{P}]$; (2) max missed cleavages, 0 ; (3) peptide length, 7-25; (4) static modification, Cys carbamidomethyl; (5) variable modification, Met oxidation; and (6) max variable modifications, 3 . The following transition settings were used: (1) precursor charges, 2 and 3; (2) ion charges, 1 and 2; (3) ion types, b, y and $\mathrm{p}$; (4) product ions, from ion 3 to the last ion; and (5) ion match tolerance, $0.02 \mathrm{Da}$. The peptide and protein information has been provided as Additional file 4: Table S4. 


\section{Quantitative real-time RT-PCR}

Total RNA for real-time quantitative RT-PCR was isolated from tissues using RNAiso Reagent (TaKaRa, Tokyo, Japan) and reverse transcripted into the single strand cDNA. Primers were designed using the Primer Express software version 1.5 (Applied Biosystems, Foster City, CA, USA) (Additional file 2: Table S2). Quantification of mRNA was performed using the Thermo Q50 (Thermo Fisher Scientific) with PrimeScript ${ }^{\text {TM }}$ RTPCR Kit (TaKaRa, Tokyo, Japan).

\section{Western blotting}

Liver samples were homogenized in lysis buffer $(10 \mathrm{mM}$ HEPES, pH 7.9, $150 \mathrm{mM} \mathrm{NaCl}, 1 \mathrm{mM}$ EDTA, 0.6\% NP-40, $0.5 \mathrm{mM}$ PMSF). Samples were then sonicated and incubated for $30 \mathrm{~min}$ on ice. Cellular debris was removed by centrifugation at 10,000 rpm. Protein concentrations of each sample were determined. Samples containing equal amounts of protein in equal volumes of sample buffer were separated in a denaturing $10 \%$ polyacrylimide gel and transferred to a $0.1 \mu \mathrm{m}$ pore nitrocellulose membrane. Nonspecific binding sites were blocked with trisbuffered saline (TBS; $40 \mathrm{mM}$ Tris, $\mathrm{pH}$ 7.6, $300 \mathrm{mM} \mathrm{NaCl}$ ) containing 5\% non-fat dry milk for $1 \mathrm{~h}$ at room temperature. Membranes were then incubated with antibodies to AXL (1:1000, CST, C89E7) or ECM1 (1:1000, Proteintech, 11,521-1-AP) in TBS with $0.1 \%$ Tween 20 (TBST). Membranes were washed and incubated with secondary antibodies conjugated to horseradish peroxidase. Immunoreactive proteins were detected by enhanced chemiluminescence.

\section{Results}

\section{Stepwise workflow based on TMT-based LC-MS/MS} to select and evaluate the protein signatures of the hepatic $\mathrm{I} / \mathrm{R}$ and control groups

For the purpose of this study, liver biopsy samples were collected from hepatic hemangioma patients who underwent hepatectomy prior to the Pringle maneuver (Control group) and $10 \mathrm{~min}$ after the restoration of blood supply (I/R group). Then, TMT labeling, high-performance liquid chromatography, and mass spectrometry-based quantitative proteomics were carried out. The general experimental strategy is illustrated in Fig. 1. A total of 5257 proteins were quantitatively identified in samples from the $I / R$ and control groups. Compared with the control group, 245 proteins displayed significant changes in their expression levels in the I/R group. Of these total proteins, 142 proteins were upregulated (the right part of the axis), and 103 proteins were downregulated (the left part of the axis). Differentially expressed proteins with $p$-values $<0.05$ and those with $p$-values $<0.01$ are detailed

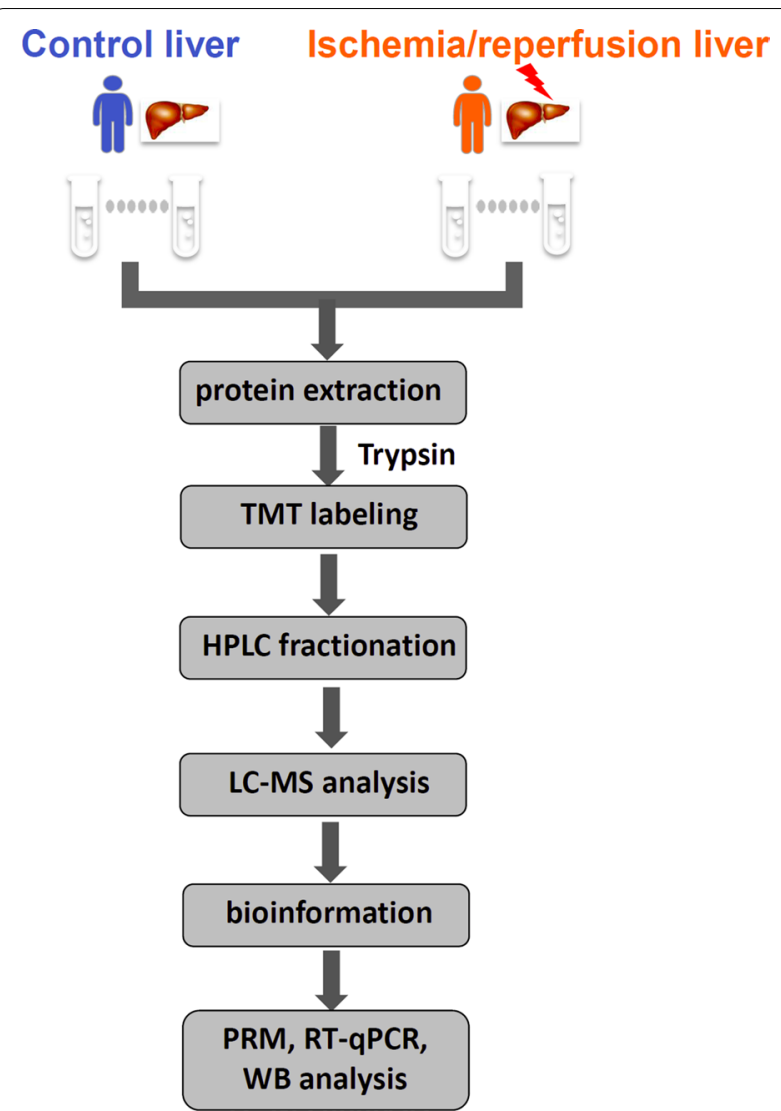

Fig. 1 Flowchart detailing the experiments including the sample preparation, data acquisition, and data analysis performed in this study. The protein peptides digested by liver biopsies were collected from six patients with hepatic hemangioma underwent hepatectomy prior to Pringle maneuver (Control group) and $10 \mathrm{~min}$ after restoration of blood supply (Ischemia/reperfusion group) respectively, then these samples were subjected to TMT labeling, HPLC fractionation and biological analysis after LC-MS/MS, and verified by PRM, qPCR and western blotting

in Fig. 2. The list of significantly regulated proteins, together with their $\log _{2}$ changes, corresponding $p$-values, and relevant biological processes, are also shown in Table 1 (more details are provided in Additional file 1: Table S1).

\section{Functional classification of differentially expressed proteins upon hepatic I/R treatment}

To elucidate functional differences between the upregulated and downregulated proteins, the quantified proteins were analyzed by three types of enrichment-based clustering analyses: Gene ontology (GO) enrichment-based clustering analysis, protein domain enrichment-based clustering analysis and KEGG pathway enrichment-based clustering analysis. Gene ontology analysis of biological processes, cellular compartments and molecular functions was used to analyze the biological functions of 


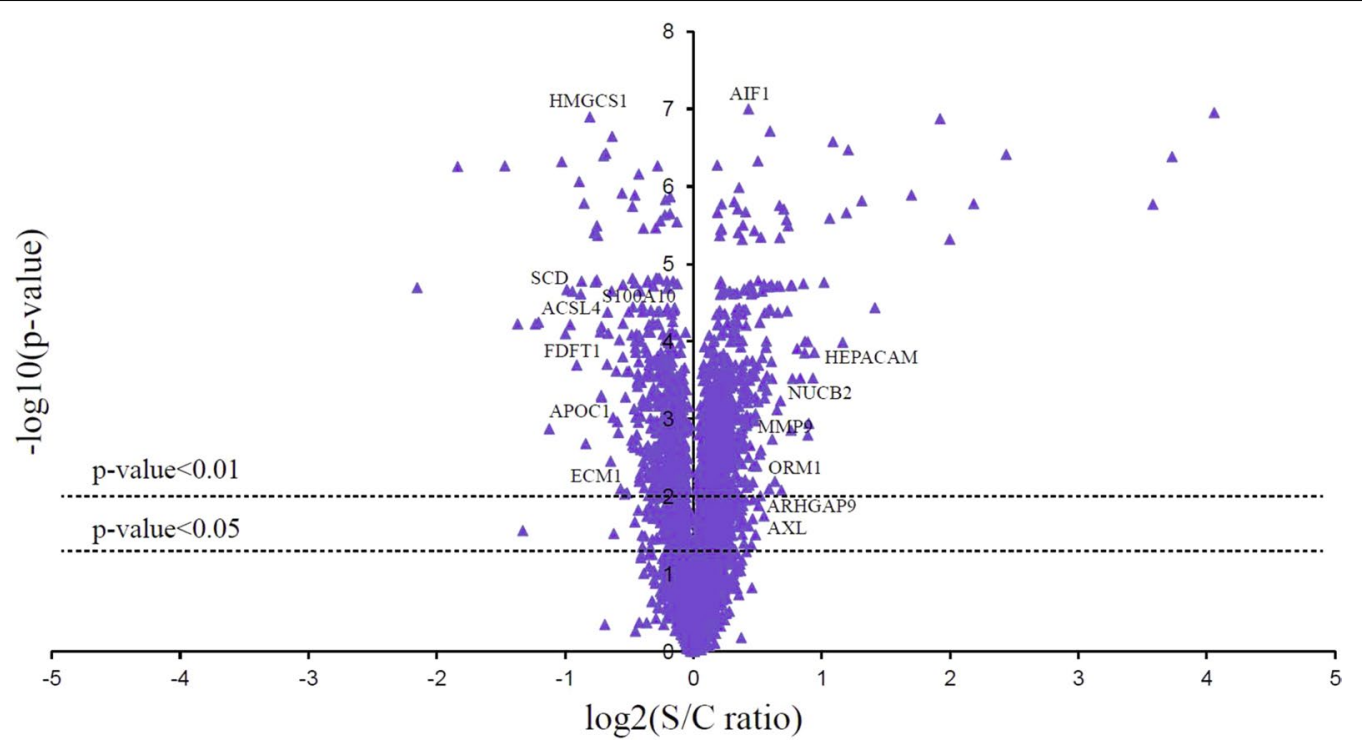

Fig. 2 Volcano plot of proteins with the most significantly different abundance levels between ischemia/reperfusion and control livers. Negative $\log _{10} p$-values are plotted logarithmically against the $\log _{2}$ protein ratios. Increased protein levels are presented on the positive $X$-axis, and decreased levels are presented on the negative $X$-axis. The differentially expressed proteins of $p$ value $<0.05$ and $p$ value $<0.01$ were detailed respectively

the differentially expressed proteins. According to their molecular functions, these proteins whose expression was altered are strongly associated with binding and catalytic activity. In addition, a majority of the differentially expressed proteins were found to be located in cells and organelles (Fig. 3 and Additional file 3: Table S3). According to biological process analysis, upregulated proteins were mainly associated with single-organism and cellular processes and responses to stimuli (Fig. 3A). Downregulated proteins were mostly associated with single-organism, cellular and metabolic biological processes (Fig. 3B). By using protein domain enrichment-based clustering analysis, the results of which were consistent with those of molecular function and biological process analyses, we observed that upregulated proteins were mostly associated with immunoglobulin-like and Glutathione-Stransferase domains. Furthermore, the downregulated proteins were mainly associated with synthetase domains (Additional file 5: Figure S1). These results suggested that these differentially expressed proteins are mainly involved in biological processes and molecular functions, especially those in response to stimuli; cellular components; and metabolic processes.

\section{Enrichment analysis of differentially expressed proteins upon hepatic I/ R treatment}

According to gene ontology enrichment analysis, upregulated differentially expressed proteins were associated with the defense, immune and inflammatory response pathways (Fig. 4a). In terms of their molecular functions, these proteins were closely related to the binding of serine peptidases, hydrolases and glutathione transferase and oxygen binding. In addition, most of the differentially expressed proteins were distributed throughout the cell and closely related to secretory proteins. Downregulated proteins were mostly associated with metabolic processes, and their molecular functions were mainly related to oxidoreductase function (Fig. 4b). KEGG-based functional enrichment analysis was also performed and showed that the upregulated proteins were mainly related to the immune network and inflammation (Fig. 4Cc). Proteins that were downregulated after I/R were enriched in many important processes, including metabolic pathways, steroid biosynthesis, retinol metabolism, steroid hormone biosynthesis, arachidonic acid and fatty acid metabolism (Fig. 4d). For more details on the functions of the differentially expressed proteins after ischemia/reperfusion, cluster analysis based on GO and KEGG enrichment was performed (Additional file 6: Figure S2). We used a significant fold-change ratio of 1.3 and performed the above clustering analyses by dividing all proteins with significantly differential expression into four quantiles (Q1-Q4) according to their L/H ratios as follows: Q1 $(\leq 0.77), \mathrm{Q} 2(0.77<$ ratio $\leq 0.83), \mathrm{Q} 3(1.2<$ ratio $\leq 1.3)$ and Q4 (>1.3) to determine the biological functions of proteins with a large change in expression (1.3 or 0.77 ) or a relatively small change in expression (1.2-1.3 or 0.77 0.83 ) upon $I / R$ treatment. The presence of functional pathway blocks and the functional descriptions of different sets of differentially expressed proteins indicated the 
Table 1 List of significantly regulated proteins in ischemia/reperfusion group versus control group using LC-MS/MS approach

\begin{tabular}{|c|c|c|c|c|c|c|}
\hline No. & Protein accession & Protein name & Gene name & $\log _{2}$ of av. ratio & $p$-value & Biological process \\
\hline 1 & P00973 & 2'-5'-Oligoadenylate synthetase 1 & OAS1 & $-0.225 \downarrow$ & 0.00002 & $\begin{array}{l}\text { Activate of latent RNase } L \text { and induce } \\
\text { viral RNA degradation }\end{array}$ \\
\hline 2 & Q2TB90 & Hexokinase domain containing 1 & HKDC1 & $-0.361 \downarrow$ & 0.00000 & $\begin{array}{l}\text { A member of the hexokinase involved in } \\
\text { glucose metabolism }\end{array}$ \\
\hline 3 & Q96AM1 & MAS related GPR family member $F$ & MRGPRF & $-0.426 \downarrow$ & 0.00006 & $\begin{array}{l}\text { Regulate nociceptor function and/or } \\
\text { development }\end{array}$ \\
\hline 4 & Q9UBS3 & DnaJ (Hsp40) homolog & DNAJB9 & $-0.433 \downarrow$ & 0.00006 & $\begin{array}{l}\text { Induced by ER stress and protect } \\
\text { stressed cells from apoptosis }\end{array}$ \\
\hline 5 & О00767 & Stearoyl-CoA desaturase & SCD & $-0.491 \downarrow$ & 0.00002 & $\begin{array}{l}\text { An enzyme involved in fatty acid } \\
\text { biosynthesis }\end{array}$ \\
\hline 6 & Q9UNA1 & Rho GTPase activating protein 26 & ARHGAP26 & $-0.54 \downarrow$ & 0.00000 & $\begin{array}{l}\text { A GTPase activating protein that binds } \\
\text { to focal adhesion kinase }\end{array}$ \\
\hline 7 & P20591 & Interferon-inducible protein P78 & $M \times 1$ & $-0.544 \downarrow$ & 0.00002 & $\begin{array}{l}\text { A GTP-metabolizing protein involved in } \\
\text { the cellular antiviral response }\end{array}$ \\
\hline 8 & Q01581 & HMG-CoA synthase & HMGCS1 & $-0.572 \downarrow$ & 0.00000 & Regulation of cholesterol biosynthesis \\
\hline 9 & P05161 & ISG15 ubiquitin-like modifier & ISG15 & $-0.588 \downarrow$ & 0.00002 & $\begin{array}{l}\text { A ubiquitin-like protein upon activation } \\
\text { by IFN- } \alpha \text { and IFN- } \beta\end{array}$ \\
\hline 10 & P37268 & Squalene synthase & FDFT1 & $-0.609 \downarrow$ & 0.00006 & $\begin{array}{l}\text { Catalyze the reaction to form squalene } \\
\text { in cholesterol biosynthesis }\end{array}$ \\
\hline 11 & Q14397 & Glucokinase regulator & GCKR & $-0.609 \downarrow$ & 0.00052 & $\begin{array}{l}\text { A regulatory protein that inhibits glu- } \\
\text { cokinase in liver }\end{array}$ \\
\hline 12 & Q8N126 & Cell adhesion molecule 3 & CADM3 & $-0.631 \downarrow$ & 0.00008 & $\begin{array}{l}\text { A calcium-independent cell-cell adhe- } \\
\text { sion protein }\end{array}$ \\
\hline 13 & Q9Y6K5 & Interferon-induced protein 56 & IFIT1 & $-0.643 \downarrow$ & 0.00002 & $\begin{array}{l}\text { Inhibit expression of viral messenger } \\
\text { RNAs }\end{array}$ \\
\hline 14 & Q9UK22 & F-box protein 2 & $\mathrm{FBXO2}$ & $-0.664 \downarrow$ & 0.00108 & $\begin{array}{l}\text { Function in phosphorylation-dependent } \\
\text { ubiquitination }\end{array}$ \\
\hline 15 & Q9TQE0 & MHC class II HLA-DR beta 1 chain & HLA-DRB1 & $-0.683 \downarrow$ & 0.00016 & $\begin{array}{l}\text { Present peptides derived from extracel- } \\
\text { lular proteins }\end{array}$ \\
\hline 16 & O60488 & Long-Chain Acyl-CoA synthetase 4 & ACSL4 & $-0.684 \downarrow$ & 0.00006 & $\begin{array}{l}\text { Play a key role in lipid biosynthesis and } \\
\text { fatty acid degradation }\end{array}$ \\
\hline 17 & 075604 & Ubiquitin specific peptidase 2 & USP2 & $-0.693 \downarrow$ & 0.00052 & $\begin{array}{l}\text { A ubiquitin-specific protease required } \\
\text { for TNF-a-induced NF-kB }\end{array}$ \\
\hline 18 & Q16610 & Extracellular matrix protein 1 & ECM1 & $-0.698 \downarrow$ & 0.00896 & $\begin{array}{l}\text { Involved in angiogenesis and tumor } \\
\text { biology }\end{array}$ \\
\hline 19 & Q9NR19 & Acetyl-coenzyme a synthetase 2 & ACSS2 & $-0.717 \downarrow$ & 0.00008 & $\begin{array}{l}\text { Activation of acetate for use in lipid } \\
\text { synthesis and energy generation }\end{array}$ \\
\hline 20 & Q15800 & Methylsterol monooxygenase 1 & MSMO1 & $-0.72 \downarrow$ & 0.00000 & $\begin{array}{l}\text { Localized to the ER membrane function } \\
\text { in cholesterol biosynthesis }\end{array}$ \\
\hline 21 & P11509 & Cytochrome P450 family 2 & CYP2A6 & $-0.722 \downarrow$ & 0.00004 & $\begin{array}{l}\text { Involved in of cholesterol, steroids and } \\
\text { other lipids }\end{array}$ \\
\hline 22 & Q8TF05 & Phosphatase 4 regulatory subunit 1 & PPP4R1 & $-0.729 \downarrow$ & 0.02137 & $\begin{array}{l}\text { Serine/threonine protein phosphatase } 4 \\
\text { (PP4) to regulate HDAC3 }\end{array}$ \\
\hline 23 & P14555 & Phospholipase A2 group IIA & PLA2G2A & $-0.74 \downarrow$ & 0.00038 & $\begin{array}{l}\text { Participate in phospholipid metabolism } \\
\text { in biomembranes }\end{array}$ \\
\hline 24 & P07355 & Annexin A2 & ANXA2 & $-0.746 \downarrow$ & 0.00638 & $\begin{array}{l}\text { Members of this calcium-dependent } \\
\text { phospholipid-binding protein family }\end{array}$ \\
\hline 25 & 094760 & Dimethylargininase-1 & DDAH1 & $-0.751 \downarrow$ & 0.00504 & Plays a role in nitric oxide generation \\
\hline 26 & Q9NYL2 & MAPKKK20 & MAP3K20 & $-0.755 \downarrow$ & 0.00034 & $\begin{array}{l}\text { A member of MAPKKK family and play a } \\
\text { role in cell cycle checkpoint }\end{array}$ \\
\hline 27 & P60903 & S100 calcium binding protein A10 & S100A10 & $-0.758 \downarrow$ & 0.00004 & $\begin{array}{l}\text { Involved in the regulation of cell cycle } \\
\text { progression and differentiation }\end{array}$ \\
\hline 28 & P02654 & Apolipoprotein C1 & APOC1 & $-0.762 \downarrow$ & 0.00068 & $\begin{array}{l}\text { Play a central role in HDL and VLDL } \\
\text { metabolism }\end{array}$ \\
\hline
\end{tabular}


Table 1 (continued)

\begin{tabular}{|c|c|c|c|c|c|c|}
\hline No. & Protein accession & Protein name & Gene name & $\log _{2}$ of av. ratio & $p$-value & Biological process \\
\hline 29 & Q15582 & Transforming growth factor $\beta$ & TGFBI & $-0.769 \downarrow$ & 0.00258 & $\begin{array}{l}\text { Modulate cell adhesion and serves as a } \\
\text { ligand for several integrins }\end{array}$ \\
\hline 30 & Q9H6E4 & Coiled-coil domain containing 134 & CCDC134 & $-0.769 \downarrow$ & 0.03265 & $\begin{array}{l}\text { Inhibit ERK and JNK signal to suppress } \\
\text { cell migration and invasion }\end{array}$ \\
\hline 31 & P02750 & Leucine rich alpha-2-glycoprotein 1 & LRG1 & $1.301 \uparrow$ & 0.00032 & $\begin{array}{l}\text { Protein-protein interaction, and cell } \\
\text { adhesion and development }\end{array}$ \\
\hline 32 & P09917 & Arachidonate 5-lipoxygenase & ALOX5 & $1.302 \uparrow$ & 0.03072 & $\begin{array}{l}\text { Synthesis of leukotrienes to mediate } \\
\text { inflammatory and allergy }\end{array}$ \\
\hline 33 & P14780 & Matrix metallopeptidase 9 & MMP9 & $1.304 \uparrow$ & 0.00132 & $\begin{array}{l}\text { Breakdown of extracellular matrix in } \\
\text { tissue remodeling }\end{array}$ \\
\hline 34 & P05164 & Myeloperoxidase & MPO & $1.306 \uparrow$ & 0.00000 & $\begin{array}{l}\text { Host defense system of polymorphonu- } \\
\text { clear leukocytes }\end{array}$ \\
\hline 35 & P09601 & Heme oxygenase 1 & HMOX1 & $1.309 \uparrow$ & 0.00046 & Cytoprotective effects against apoptosis \\
\hline 36 & P30530 & $\mathrm{AXL}$ receptor tyrosine kinase & $A X L$ & $1.317 \uparrow$ & 0.02248 & $\begin{array}{l}\text { Tyrosine kinase receptor involved in } \\
\text { growth, migration, aggregation }\end{array}$ \\
\hline 37 & Q9BYE9 & Cadherin related family member 2 & $\mathrm{CDHR2}$ & $1.322 \uparrow$ & 0.00610 & $\begin{array}{l}\text { Calcium-dependent cell-cell adhesion } \\
\text { molecules }\end{array}$ \\
\hline 38 & Q9BRR9 & Rho GTPase activating protein 9 & ARHGAP9 & $1.325 \uparrow$ & 0.01110 & $\begin{array}{l}\text { A member of the Rho-GAP family of } \\
\text { GTPase activating proteins }\end{array}$ \\
\hline 39 & P55290 & Cadherin 13 & $\mathrm{CDH} 13$ & $1.332 \uparrow$ & 0.00762 & $\begin{array}{l}\text { Protects cells from apoptosis due to } \\
\text { oxidative stress }\end{array}$ \\
\hline 40 & P02776 & Platelet factor 4 & PF4 & $1.346 \uparrow$ & 0.00314 & A member of the CXC chemokine family \\
\hline 41 & P55008 & Allograft inflammatory factor 1 & AlF1 & $1.347 \uparrow$ & 0.00000 & $\begin{array}{l}\text { Play a role in macrophage activation and } \\
\text { function }\end{array}$ \\
\hline 42 & A0A075B6K5 & Immunoglobulin lambda variable & IGLV3-9 & $1.357 \uparrow$ & 0.00054 & Participates in the antigen recognition \\
\hline 43 & Q15165 & Paraoxonase 2 & PON2 & $1.375 \uparrow$ & 0.00018 & $\begin{array}{l}\text { A cellular antioxidant, protecting cells } \\
\text { from oxidative stress }\end{array}$ \\
\hline 44 & Q9ULU4 & Zinc finger MYND-type containing 8 & ZMYND8 & $1.379 \uparrow$ & 0.00650 & $\begin{array}{l}\text { Down-regulation of diverse metastasis- } \\
\text { associated genes }\end{array}$ \\
\hline 45 & Q8TD30 & Glutamic-alanine transaminase & GPT2 & $1.381 \uparrow$ & 0.01102 & $\begin{array}{l}\text { Catalyzes the reversible transamination } \\
\text { between alanine and glutamate }\end{array}$ \\
\hline 46 & P02763 & Orosomucoid 1 & ORM1 & $1.384 \uparrow$ & 0.00396 & An acute-phase reactant \\
\hline 47 & Q9H799 & $\begin{array}{l}\text { Ciliogenesis and planar polarity effec- } \\
\text { tor } 1\end{array}$ & C5orf42 & $1.399 \uparrow$ & 0.00052 & $\begin{array}{l}\text { Establishment of cell polarity required } \\
\text { for directional cell migration }\end{array}$ \\
\hline 48 & P09210 & Glutathione S-transferase alpha 2 & GSTA2 & $1.422 \uparrow$ & 0.01306 & Glutathione S-transferase \\
\hline 49 & P05413 & Fatty acid binding protein 3 & FABP3 & $1.44 \uparrow$ & 0.00254 & $\begin{array}{l}\text { Participate in intracellular metabolism of } \\
\text { long-chain fatty acids }\end{array}$ \\
\hline 50 & P80303 & Nucleobindin 2 & NUCB2 & $1.458 \uparrow$ & 0.00034 & Have a role in calcium homeostasis \\
\hline 51 & Q96JA1 & Leucine-rich repeat protein LRIG1 & LRIG1 & $1.465 \uparrow$ & 0.00002 & $\begin{array}{l}\text { A feedback negative regulator of signal- } \\
\text { ing by receptor tyrosine kinases }\end{array}$ \\
\hline 52 & Q5R3K3 & Calcium homeostasis modulator 6 & CALHM6 & $1.608 \uparrow$ & 0.00832 & Calcium homeostasis \\
\hline 53 & 000479 & $\begin{array}{l}\text { High mobility group nucleosomal } \\
\text { binding domain } 4\end{array}$ & HMGN4 & $1.629 \uparrow$ & 0.00000 & $\begin{array}{l}\text { Reduce the compactness of the chro- } \\
\text { matin fiber in nucleosomes }\end{array}$ \\
\hline 54 & Q14CZ8 & Hepatocyte cell adhesion molecule & HEPACAM & $1.923 \uparrow$ & 0.00014 & $\begin{array}{l}\text { Involved in cell motility and cell-matrix } \\
\text { interactions }\end{array}$ \\
\hline 55 & P30711 & Glutathione S-transferase Theta 1 & GSTT1 & $2.087 \uparrow$ & 0.00000 & A member of glutathione s-transferase \\
\hline 56 & O94885 & SAM and $\mathrm{SH} 3$ domain containing 1 & SASH1 & $2.283 \uparrow$ & 0.00000 & $\begin{array}{l}\text { A scaffold protein involved in the tru } \\
\text { signaling pathway }\end{array}$ \\
\hline 57 & Q86VW2 & GTP-rho-binding protein 2 & RHPN2 & $3.246 \uparrow$ & 0.00000 & $\begin{array}{l}\text { A member of rho-gtpase binding } \\
\text { proteins }\end{array}$ \\
\hline 58 & P02741 & C-reactive protein & CRP & $5.412 \uparrow$ & 0.00000 & $\begin{array}{l}\text { Acute phase response to tissue injury, } \\
\text { infection, or inflammatory stimuli }\end{array}$ \\
\hline 59 & Q03013 & Glutathione S-transferase Mu 4 & GSTM4 & $11.968 \uparrow$ & 0.00000 & A member of glutathione S-transferase \\
\hline 60 & P09488 & Glutathione S-transferase Mu 1 & GSTM1 & $13.258 \uparrow$ & 0.00000 & A member of glutathione S-transferase \\
\hline
\end{tabular}




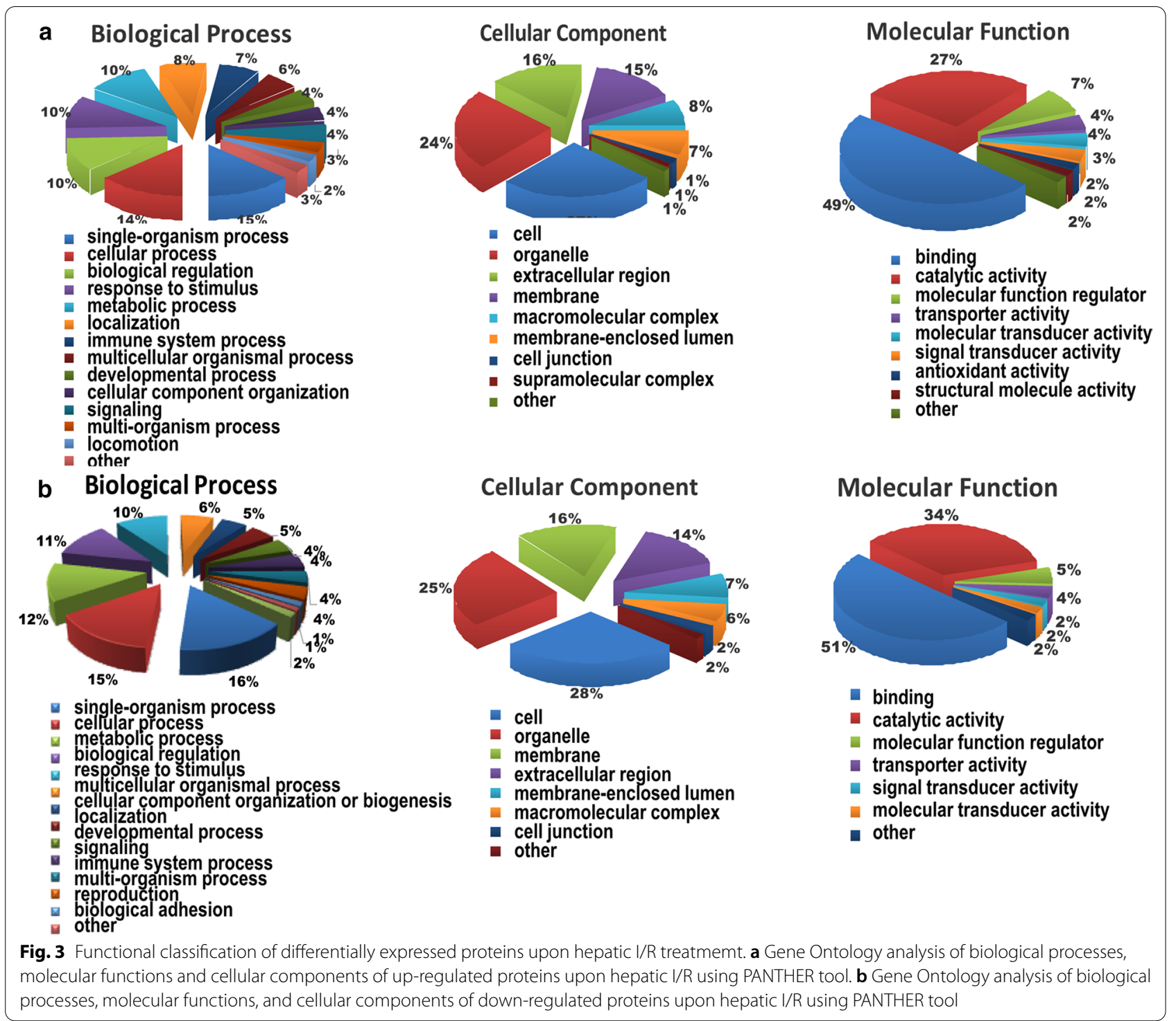

degree of enrichment. Red indicates strong enrichment, and blue indicates weak enrichment. Biological process clustering analysis showed that the upregulated proteins were closely related to secretion, immunity, the response to stimuli and cytokines. In contrast, the downregulated proteins were mostly associated with metabolism (Additional file 6: Figure S2a). As shown by molecular functional clustering analysis, the altered proteins were closely related to receptor activity, binding, and transferase activity (Additional file 6: Fig. S2b). By cellular component clustering analysis, the upregulated proteins were found to be localized to the nuclear membrane and plasma membrane fractions, while the downregulated proteins were mainly localized to the endoplasmic reticulum and nuclear membrane (Additional file 6:
Figure S2c). KEGG pathway clustering analysis showed that the upregulated proteins were involved in immune and inflammatory responses, such as the PPAR signaling pathway (Additional file 7: Figure S3). Downregulated proteins were mostly involved in various metabolic and biosynthetic pathways (Additional file 6: Figure S2d). Taken together, these data demonstrated that the upregulated proteins were involved in immunity and inflammatory responses and that the downregulated proteins were involved in metabolic pathways.

\section{Validation of differentially expressed proteins upon hepatic I/R using PRM, WB, and qPCR}

High-throughput techniques were very effective in elucidating the differential abundance of proteins in the 


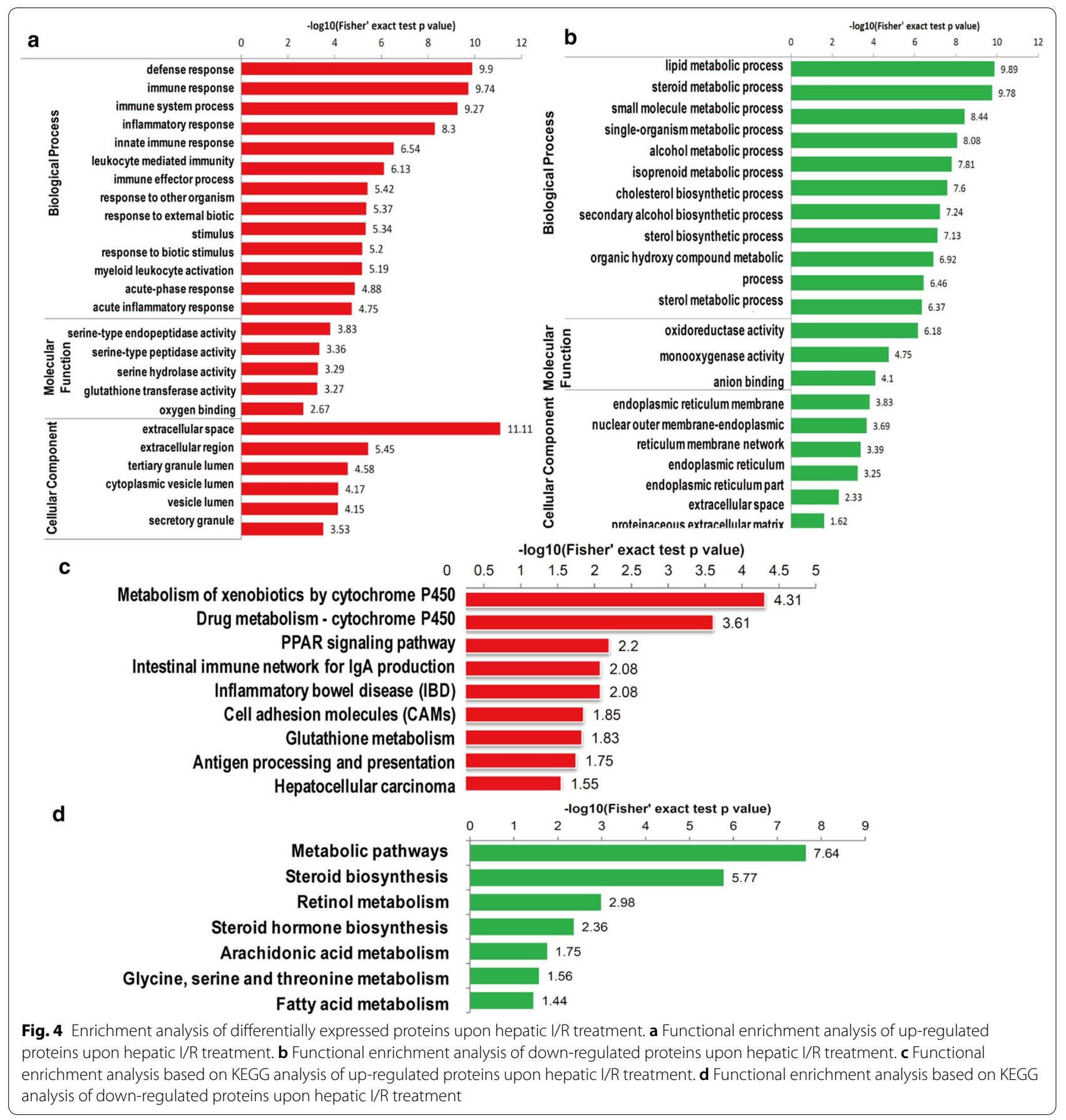

hepatic $\mathrm{I} / \mathrm{R}$ and control groups. To confirm the proteomic results and further extend our analysis of differentially expressed proteins, we analyzed both sets of samples using PRM-based validation proteomics, real-time quantitative PCR, and western blotting. The PRM data showed that the average number of individuals observed per group was consistent with the ratio of pooled samples (Table 2 and Additional file 4: Table S4). Next, we
Table 2 Comparison between TMT and PRM results

\begin{tabular}{llll}
\hline Protein accession & Protein gene & S/C ratio(PRM) & S/C ratio(TMT) \\
\hline P60908 & S100A10 & 0.56 & 0.76 \\
P02654 & APOC1 & 0.57 & 0.76 \\
P02763 & ORM1 & 1.39 & 1.38 \\
P80303 & NUCB2 & 1.55 & 1.46 \\
\hline
\end{tabular}



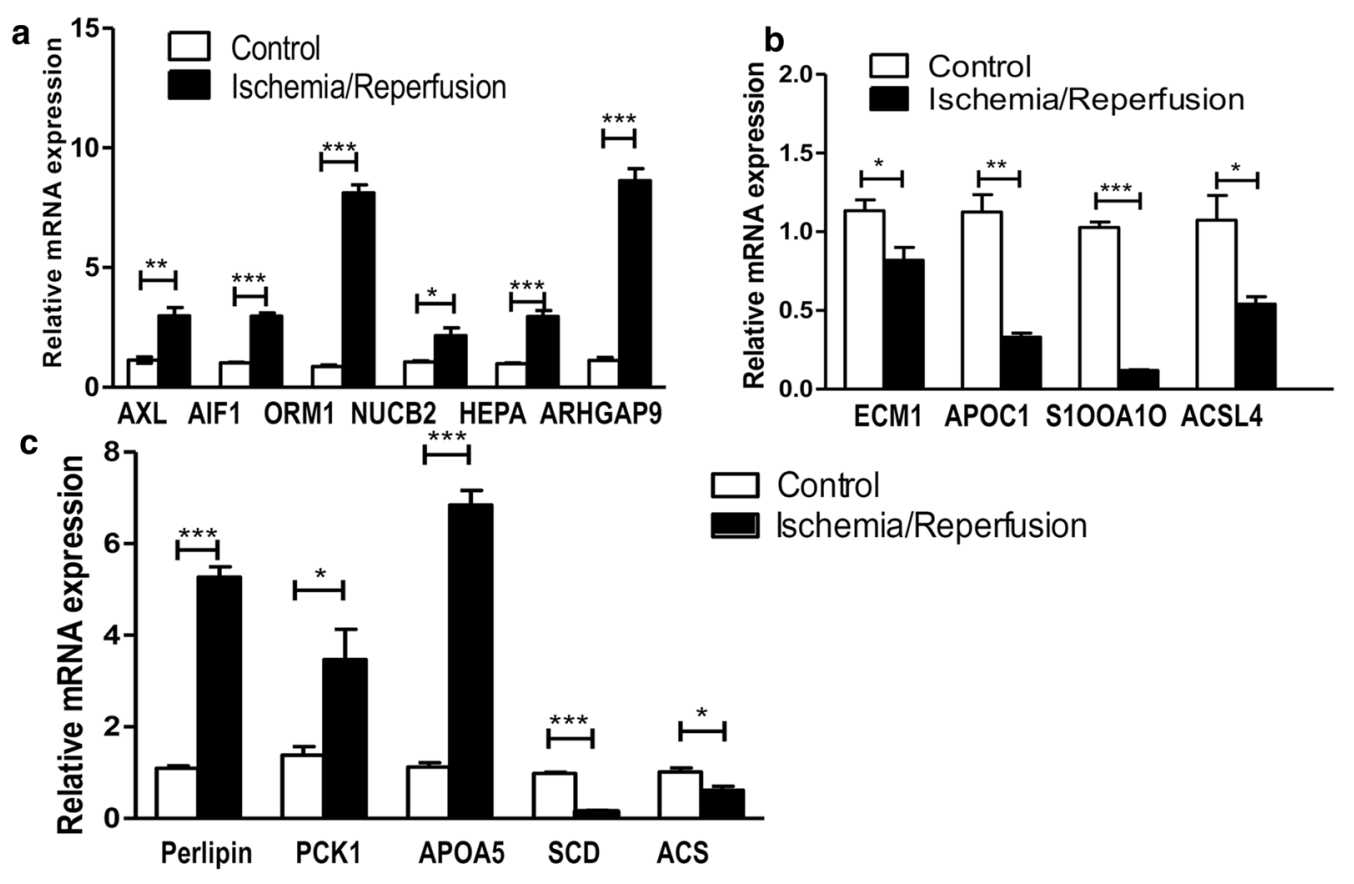

d

$\begin{array}{lllllllllll}\text { C1 } & \text { C2 } & \text { C3 } & \text { S1 } & \text { S2 } & \text { S3 }\end{array}$
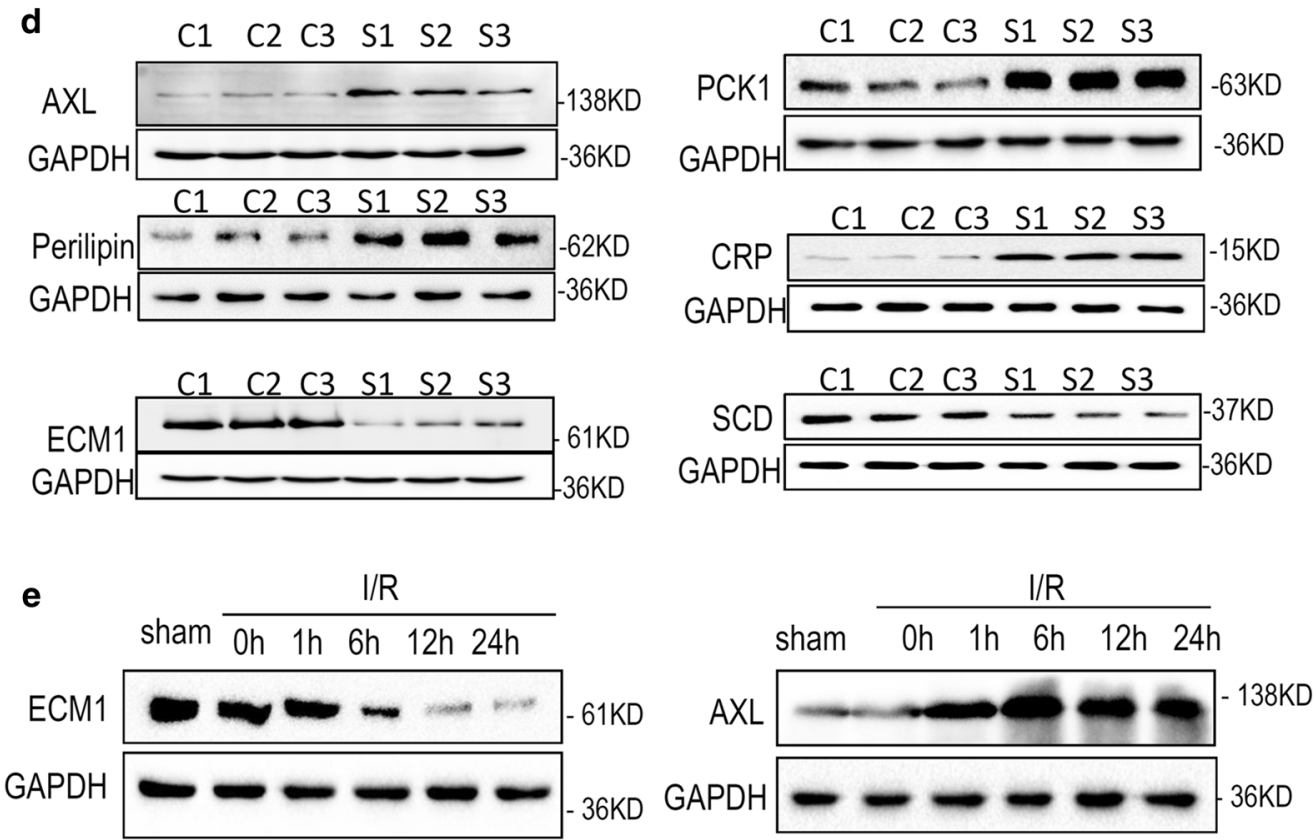

Fig. 5 Validation of ischemic groups and control groups using western blotting and qPCR. a The mRNA expressions of up-regulated proteins, such as, AXL, AIF1, ORM1, NUCB2, HEPA, and ARHGAP9 of control and ischemia/reperfusion livers were verified using quantitative real-time analysis. The error bars represent the mean \pm SD. Statistical significance was analyzed with unpaired Student's $t$-test $\left({ }^{*} p<0.05,{ }^{* *} p<0.01,{ }^{* * *} p<0.001\right)$. b The mRNA expressions of down-regulated proteins, such as, ECM1, APOC1, S1OOA1O and ACSL4 of control and ischemia/reperfusion livers were verified using quantitative real-time analysis. The error bars represent the mean \pm SD. Statistical significance was analyzed with unpaired Student's $t$-test $\left({ }^{*} p<0.05,{ }^{* *} p<0.01,{ }^{* * *} p<0.001\right)$. c The mRNA expressions of five PPAR signaling pathway-related proteins Perlipin, PCK1, APOA5, SCD and ACS were detected. $\mathbf{d}$ Western blot analysis of AXL, PCK1, Perlipin, CRP, ECM1 and SCD expressions of control livers (C1, C2 and C3) and ischemia/ reperfusion livers (S1, S2 and S3). e Representative western blot analysis of ECM1 and AXL protein levels in livers from mice subjected to sham treatment or ischaemia for $1 \mathrm{~h}$ followed by reperfusion for the indicated times 
detected changes in the mRNA levels of the metabolic and inflammation-associated differentially expressed proteins ECM1, APOC1, S100A10, ACSL4, AXL, ARHGAP9, AIF1, ORM1, NUCB2 and HEPACAM (Fig. 5a, b). The PPAR signaling cascade was found to be perturbed in the human liver upon I/R treatment. Therefore, we focused on these proteins and verified their mRNA expression levels (Fig. 5c). RT-qPCR analysis showed that the mRNA levels of these proteins were consistent with our proteomic data (Fig. 5a-c). Then, we selected several representative upregulated proteins (AXL, PCK1, Perilipin and CRP) and downregulated proteins (ECM1 and SCD) and performed western blotting analysis, the results of which were also consistent with the proteomic data (Fig. 5d). Additionally, we analyzed ECM1 and AXL expression in liver lobes from mice subjected to liver $I / R$ surgery. A gradual decrease in ECM1 expression and an increase in AXL expression from 1 to $24 \mathrm{~h}$ were observed after I/R surgery (Fig. 5e). Collectively, these data further verified the results of the proteomics experiment.

\section{Discussion}

Tandem mass tag (TMT) proteomics has emerged as a new method of protein mass spectrometry and has been widely used for protein quantification and identification in the fields of cancer research $[14,15]$, neurobiology [16] and tissue analysis, such as biomarker research $[17,18]$. Accumulating evidence indicates that reperfusion following hepatic ischemia gives rise to secondary injury accompanied by structural and functional damage. However, the molecular mechanisms underlying these phenotypes remain incompletely characterized. Only a limited number of proteomic studies of liver I/R tissues were reported more than a decade ago. Previous studies used proteomic approach to identify differences in protein expression between murine subjected to hepatic ischemia and sham treatment [19, 20]. In addition, only a few databases supported reliable quantification due to the limitations of mass spectrometry at that time [21]. Novel tools that allow us to take a highthroughput and quantitative approach to determining differentially expressed proteins are now available. Therefore, we decided to apply TMT-based quantitative high-throughput mass spectrometry to characterize the proteins that are differentially expressed in the human liver during ischemia/reperfusion. A total of 5,257 proteins were quantitatively identified. Among these, 142 proteins were significantly upregulated, while 103 proteins were significantly downregulated. The upregulated proteins were mainly involved in the oxidative, immune and inflammatory pathways, and the downregulated proteins were closely associated with metabolism. Upon hepatic I/R injury, major enzymes involved in lipid and steroid synthesis, cholesterol biosynthesis, energy metabolism and amino acid metabolism were downregulated, indicating the global impairment of metabolic activity in liver tissues, which might reflect an adaptive mechanism by which the hepatocyte reduces energy and nutrient dissipation under conditions of ischemia and reperfusion. Consistently, our studies confirmed previously reported changes in the oxidative pathway upon I/R injury [20,22]. In addition, a recent study reported that a liver-selective MMP9 inhibitor eliminated ischemia/reperfusion injury and accelerated liverregeneration in rats [23]. Our study provides proteomic evidence to confirm that MMP9 expression is significantly increased in the human liver upon $\mathrm{I} / \mathrm{R}$.

However, though the great majority of proteins whose expression is altered in the liver upon $I / R$ are enzymes involved in metabolic pathways, energy and lipid metabolism, the significant involvement of the immune and inflammatory pathways during the $\mathrm{I} / \mathrm{R}$ response is particularly evident. For instance, allograft inflammatory cytokine-1 (AIF-1) was observed to be significantly elevated after hepatic ischemia/reperfusion, which is consistent with the results of a previous report in a rat model [19]. The expression of AIF-1, which modulates the immune response during macrophage and neutrophil activation, is upregulated by the cytokine IFN- $\gamma$ [24]. AIF-1 has been reported to increase the production of IL-6, IL-10, and IL-12p40 compared with control cells. AIF-1 is overexpressed in liver allografts with acute rejection after transplantation in rats [25]. We hypothesized that AIF-1 aggravates hepatocyte injury in $I / R$ via promoting inflammation. Importantly, however, the results of TMT-based quantitative proteomics analysis in our study demonstrated striking differences in other immunity- and inflammation-related proteins that have not been reported in the context of ischemia/reperfusion. Platelet factor 4 (PF4) is a small cytokine belonging to the CXC chemokine family that is also known as chemokine (C-X-C motif) ligand 4 (CXCL4). This chemokine is released from the alpha granules of activated platelets during platelet aggregation and promotes blood coagulation by moderating the effects of heparin-like molecules. Due to these roles, PF4 is predicted to play a role in inflammation [26]. C-reactive protein (CRP) was initially found to be secreted by pathogens since its level was elevated in a variety of illnesses, including cancer [27]. The later discovery of its hepatic synthesis (CRP is made in the liver.) demonstrated that CRP is a native protein. CRP is an acute-phase protein of hepatic origin that increases following IL-6 secretion by macrophages and T cells [28]. CRP is used mainly as a marker of inflammation in clinical diagnosis [27]. In the present study, we observed the increased expression of PF4 and CRP in the human liver 
upon $I / R$, suggesting that these proteins whose expression was enhanced aggravate hepatocyte injury during $\mathrm{I} / \mathrm{R}$ through inducing inflammation.

AXL, a cell surface receptor tyrosine kinase, is characterized by an extracellular structure consisting of two fibronectin type 3-like repeats and two immunoglobulinlike repeats along with its intracellular tyrosine kinase domain. Signaling pathways activated downstream of AXL include the PI3K-AKT-mTOR, NF-kB and JAK/ STAT pathways. AXL inhibits the innate immune response. The functions of activated AXL in normal tissues include the efficient clearance of apoptotic material and the inhibition of TLR-dependent inflammatory responses and natural killer cell activity [29]. ECM1 is a glycosylated protein secreted extracellularly that was found to contribute to migration and invasion in cholangiocarcinoma cells. Indeed, ECM1 has been shown to inhibit the activity of MMP9 [30]. MMP6 plays deleterious role in ischemia/reperfusion [31]. Therefore, elevating ECM1 or AXL levels could be a therapeutic strategy to ameliorate hepatic $\mathrm{I} / \mathrm{R}$ injury. SASH1 is a scaffold protein involved in the TLR4 signaling pathway that may stimulate cytokine production and endothelial cell migration. The encoded protein has also been described as a potential tumor suppressor that may negatively regulate the proliferation, apoptosis, and invasion of cancer cells. Thus, the increased levels of these immunity-related proteins indicated their potential roles in I/R injury. This finding underscores the importance and possible link between inflammation and immunity in hepatic ischemia/reperfusion injury.

Peroxisome proliferator-activated receptors (PPARs) are a family of nuclear receptors that comprises ligandmodulated transcription factors with broad tissue distributions and a wide array of target genes and functions [32]. PPARs are naturally activated by lipid-derived substrates to increase the proliferation of peroxisomes [33]. The PPAR subfamily is composed of three subtypes: PPAR $\alpha, \operatorname{PPAR} \delta / \beta$, and PPAR $\gamma$. PPAR $\alpha$ is expressed mainly in tissues with high fatty acid metabolism, including the liver, kidney, and white and brown adipose tissue. PPAR $\delta / \beta$, which is ubiquitously and abundantly expressed in a broad range of tissues, regulates fatty acid oxidation. PPAR $\gamma$ is expressed in various cell types, including brain cells and bone marrow-derived immune cells. PPARY is a ligand-activated nuclear receptor that regulates glucose and lipid metabolism, endothelial function and inflammation [34]. Here, by an initial manual query, the expression levels of the following six proteins associated with the PPAR signaling cascade were found to be significantly altered after hepatic ischemia/reperfusion: SCD, Perilipin, FABP, ACS, APOA5 and PEPCK (Additional file 7: Figure S3). Hepatic I/R appears to promote the expression of fatty acid binding Protein 3 (FABP3), SCD, Perilipin-1, PEPCK and APOA5 and inhibit the expression of ACS, indicating that the PPAR signaling cascade is perturbed in the human liver upon I/R treatment. Taken together, our observations support the hypothesis that the liver undertakes protective strategies after ischemia/reperfusion by upregulating immunity- and inflammation-associated functions and downregulating metabolism.

In this study, these differentially expressed proteins were observed within 30 min of initiation of hepatic I/R injury, which is consistent with previous literatures. $\mathrm{He}$ W et al. reported that expression of TXNIP is elevated in rat livers exposed to $30 \mathrm{~min}$ of warm ischemia [35]. Nicoud IB et al. harvested livers tissues during ischemia or after early reperfusion time points from mice subjected to $30 \mathrm{~min}$ of $70 \%$ hepatic ischemia. The result showed that sham-operated liver tissue and ischemic liver tissue harvested before reperfusion do not express MMP9; however, reperfusion for 15 or 30 min resulted in observable MMP9 in the liver [36]. Olthof PB et al. reported that Foxp3 is more strongly upregulated in the $30-\mathrm{min}$ ischemia group compared to the $60 \mathrm{~min}$ ischemia group. Foxp3 is the master regulator of regulatory $\mathrm{T}$ cells, which are induced by cytokines such as TGF- $\beta$, inhibit the development of pro-inflammatory effector $\mathrm{T}$ cells. Also, regulatory $\mathrm{T}$ cells are protective in hepatic $I / R$, which may play a role in reducing inflammatory response. Furthermore, they made the point that mouse models using $\leq 30 \mathrm{~min}$ of ischemia best reflect the clinical liver I/R injury profile in terms of liver function dynamics and type of immune response [37].

The current study has some limitations. First, for obvious reasons, one limit of this study was the inability to control the ischemia and reperfusion times during hepatectomy. Second, due to interindividual variability in the cellular response to $I / R$ injury, further studies will be devoted to evaluating the role of these specific proteins in a larger number of clinical cases. Finally, the concentrations of the relatively abundant proteins identified here are only one factor in cellular reactions to stimuli. Posttranslational modifications are important components of cellular responses that will need to be addressed in future studies.

In summary, our findings revealed multiple protein changes potentially involved in hepatic $I / R$ injury in human samples. We found that the liver upregulates immunity- and inflammation-associated functions and downregulates metabolism to undertake protective strategies upon ischemia and reperfusion stimuli. In particular, we identified a series of proteins that had not previously been reported, PF4, CRP, AXL, ECM1, SASH1, APOC1, ACSL4, ORM1 and NUCB2, as well as 
members of the PPAR signaling pathway. We anticipate that further studies of the proteins identified herein will expand our understanding of the mechanisms of hepatic $I / R$ injury, thus assisting in the eventual development of new therapeutic approaches against hepatic I/R injury.

\section{Supplementary Information}

The online version contains supplementary material available at https://doi. org/10.1186/s12014-020-09310-w.

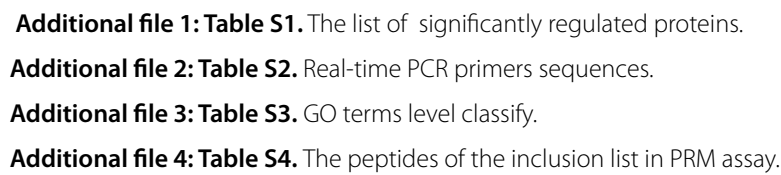
protein domains of differentially expressed proteins upon hepatic I/R treatmemt.

Additional file 6: Figure S2. The clustering analysis heat map based on GO enrichment includes three categories: a Biological Process b Cellular Component and $\mathbf{c}$ Molecular Function d Cluster analysis heat map based on KEGG pathway enrichment.

Additional file 7: Figure S3. Significantly enriched differentially expressed proteins were visualized in the PPAR signaling pathway.

\section{Acknowledgements}

This work was supported by the Natural Science Foundation of China (81970542 to Lijian Chen) and the Natural Science Foundation of Anhui Province (1708085MH190 to Lijian Chen).

\section{Authors' contributions}

JD and LC conceived and designed the experiments. HC, SQ and QY performed the experiments. HC, SQ, QY and JL analyzed the data. JD and LC wrote and critically revised the manuscript. All authors read and approved the final manuscript.

\section{Competing interests}

No conflicts of interest, financial or otherwise, are declared by the authors.

\section{Author details}

${ }^{1}$ Department of Biochemistry and Molecular Biology, School of Basic Medical Sciences, Anhui Medical University, Hefei, Anhui 230032, People's Republic of China. ${ }^{2}$ The Key Laboratory of Pathogen Biology of Anhui Province, Anhui Medical University, Hefei 230032, China. ${ }^{3}$ Department of Anesthesiology, the First Affiliated Hospital of Anhui Medical University, Hefei, Anhu 230032, People's Republic of China.

Received: 28 August 2020 Accepted: 14 December 2020 Published online: 06 January 2021

\section{References}

1. Qin JJ, Mao W, Wang X, Sun P, et al. Caspase recruitment domain 6 protects against hepatic ischemia/reperfusion injury by suppressing ASK1. Hepatol. 2018:69:1110-22

2. Robertson FP, Fuller BJ, Davidson BR. An evaluation of ischaemic preconditioning as a method of reducing ischaemia reperfusion injury in liver surgery and transplantation. J Clin Med. 2017;6:69.

3. Zhai Y, Petrowsky H, Hong JC, Busuttil RW, Kupiec-Weglinski JW. Ischaemia-reperfusion injury in liver transplantation-from bench to bedside. Nat Rev Gastroenterol Hepatol. 2013;10:79-89.

4. Oliveira THC, Marques PE, Proost P, Teixeira MMM. Neutrophils: a cornerstone of liver ischemia and reperfusion injury. Lab Invest. 2018;98:51-62
5. Konishi T, Lentsch AB. Hepatic ischemia/reperfusion: mechanisms of tissue injury, repair, and regeneration. Gene Expr. 2017;17:277-87.

6. Cannistra M, Ruggiero M, Zullo A, Gallelli G, et al. Hepatic ischemia reperfusion injury: A systematic review of literature and the role of current drugs and biomarkers. Int J Surg. 2016;33(Suppl 1):S57-70.

7. Kalogeris T, Baines CP, Krenz M, Korthuis RJ. Cell biology of ischemia/reperfusion injury. Int Rev Cell Mol Biol. 2012;298:229-317.

8. Zhang C, Huang J, An W. Hepatic stimulator substance resists hepatic ischemia/reperfusion injury by regulating Drp1 translocation and activation. Hepatology. 2017;66:1989-2001.

9. Hu C, Li L. Pre-conditions for eliminating mitochondrial dysfunction and maintaining liver function after hepatic ischaemia reperfusion. J Cell Mol Med. 2017;21:1719-31.

10. Ankney JA, Muneer A, Chen X. Relative and absolute quantitation in mass spectrometry-based proteomics. Annu Rev Anal Chem (Palo Alto Calif). 2018;11:49-77.

11. Marx V. Targeted proteomics. Nat Methods. 2013;10:19-22.

12. Schulze WX, Usadel B. Quantitation in mass-spectrometry-based proteomics. Annu Rev Plant Biol. 2010;61:491-516.

13. Udeshi ND, Svinkina T, Mertins P, Kuhn E, et al. Refined preparation and use of anti-diglycine remnant (K-epsilon-GG) antibody enables routine quantification of 10,000 s of ubiquitination sites in single proteomics experiments. Mol Cell Proteomics. 2013;12:825-31.

14. Banh RS, lorio C, Marcotte $R, X u Y$, et al. PTP1B controls non-mitochondrial oxygen consumption by regulating RNF213 to promote tumour survival during hypoxia. Nat Cell Biol. 2016;18:803-13.

15. Vartanian S, Ma TP, Lee J, Haverty PM, et al. Application of mass spectrometry profiling to establish brusatol as an inhibitor of global protein synthesis. Mol Cell Proteomics. 2016;15:1220-31.

16. Russell CL, Heslegrave A, Mitra V, Zetterberg H, et al. Combined tissue and fluid proteomics with Tandem Mass Tags to identify low-abundance protein biomarkers of disease in peripheral body fluid: an Alzheimer's Disease case study. Rapid Commun Mass Spectrom. 2017;31:153-9.

17. Paulo JA, Gaun A, Gygi SP. Global analysis of protein expression and phosphorylation levels in nicotine-treated pancreatic stellate cells. J Proteome Res. 2015:14:4246-56.

18. George PM, Mlynash M, Adams CM, Kuo CJ, et al. Novel TIA biomarkers identified by mass spectrometry-based proteomics. Int I Stroke. 2015;10:1204-11

19. Hirsch J, Hansen KC, Choi S, Noh J, et al. Warm ischemia-induced alterations in oxidative and inflammatory proteins in hepatic Kupffer cells in rats. Mol Cell Proteomics. 2006:5:979-86.

20. Xu C, Zhang X, Yu C, Lu G, et al. Proteomic analysis of hepatic ischemia/ reperfusion injury and ischemic preconditioning in mice revealed the protective role of ATP5beta. Proteomics. 2009;9:409-19.

21. Vascotto C, Cesaratto L, D'Ambrosio C, Scaloni A, et al. Proteomic analysis of liver tissues subjected to early ischemia/reperfusion injury during human orthotopic liver transplantation. Proteomics. 2006;6:3455-65.

22. Cho EH, Koh PO. Proteomic identification of proteins differentially expressed by melatonin in hepatic ischemia-reperfusion injury. J Pineal Res. 2010;49:349-55.

23. Wang X, Maretti-Mira AC, Wang L, DeLeve LD. Liver-selective mmp-9 inhibition in the rat eliminates ischemia-reperfusion injury and accelerates liver regeneration. Hepatology. 2018. https://doi.org/10.1002/hep.30169.

24. Deininger $\mathrm{MH}$, Meyermann $\mathrm{R}$, Schluesener $\mathrm{HJ}$. The allograft inflammatory factor-1 family of proteins. FEBS Lett. 2002;514:115-21.

25. Autieri MV, Kelemen S, Thomas BA, Feller ED, et al. Allograft inflammatory factor-1 expression correlates with cardiac rejection and development of cardiac allograft vasculopathy. Circulation. 2002;106:2218-23.

26. Eisman R, Surrey S, Ramachandran B, Schwartz E, Poncz M. Structural and functional comparison of the genes for human platelet factor 4 and PF4alt. Blood. 1990;76:336-44.

27. Pepys MB, Hirschfield GM. C-reactive protein: a critical update. J Clin Invest. 2003:111:1805-12.

28. Thompson D, Pepys MB, Wood SP. The physiological structure of human C-reactive protein and its complex with phosphocholine. Structure. 1999;7:169-77.

29. Gay CM, Balaji K, Byers LA. Giving AXL the axe: targeting $A X L$ in human malignancy. Br J Cancer. 2017;116:415-23. 
30. Fujimoto N, Terlizzi J, Aho S, Brittingham R, et al. Extracellular matrix protein 1 inhibits the activity of matrix metalloproteinase 9 through highaffinity protein/protein interactions. Exp Dermatol. 2006;15:300-7.

31. Turner RJ, Sharp FR. Implications of MMP9 for Blood Brain Barrier Disrup tion and Hemorrhagic Transformation Following Ischemic Stroke. Front Cell Neurosci. 2016;10:56.

32. Janani C, Ranjitha Kumari BD. PPAR gamma gene-a review. Diabetes Metab Syndr. 2015;9:46-50.

33. Evans RM, Barish GD, Wang YX. PPARs and the complex journey to obesity. Nat Med. 2004;10:355-61.

34. Wang S, Dougherty EJ, Danner RL. PPARgamma signaling and emerging opportunities for improved therapeutics. Pharmacol Res. 2016;111:76-85.

35. He W, Ye S, Zeng C, Xue S, et al. Hypothermic oxygenated perfusion (HOPE) attenuates ischemia/reperfusion injury in the liver through inhibition of the TXNIP/NLRP3 inflammasome pathway in a rat model of donation after cardiac death. FASEB J. 2018. https://doi.org/10.1096/ fj.201800028RR.

36. Nicoud IB, Jones CM, Pierce JM, Earl TM, et al. Warm hepatic ischemiareperfusion promotes growth of colorectal carcinoma micrometastases in mouse liver via matrix metalloproteinase-9 induction. Can Res. 2007;67:2720-8.

37. Olthof PB, van Golen RF, Meijer B, van Beek AA, et al. Warm ischemia time-dependent variation in liver damage, inflammation, and function in hepatic ischemia/reperfusion injury. Biochim Biophys Acta Mol Basis Dis . 2017; 1863:375-85.

\section{Publisher's Note}

Springer Nature remains neutral with regard to jurisdictional claims in published maps and institutional affiliations.
Ready to submit your research? Choose BMC and benefit from:

- fast, convenient online submission

- thorough peer review by experienced researchers in your field

- rapid publication on acceptance

- support for research data, including large and complex data types

- gold Open Access which fosters wider collaboration and increased citations

- maximum visibility for your research: over $100 \mathrm{M}$ website views per year

At BMC, research is always in progress.

Learn more biomedcentral.com/submissions 